http://jmscr.igmpublication.org/home/ ISSN (e)-2347-176x ISSN (p) 2455-0450

crossref DOI: https://dx.doi.org/10.18535/jmscr/v7i12.68

Journal Of Medical Science And Clinical Research

\title{
Estimations of Lipid Profile in Smoker and non smoker as a Predictor of Atherosclerosis in Indian Patients
}

\author{
Authors \\ Dr Pankaj Bhushan ${ }^{1}$, Dr Usha Kumari ${ }^{*}$, Dr Kanchan Kumari ${ }^{3}$ \\ ${ }^{1}$ Assist. Professor, Deptt. of Biochemistry , A.N.M.M. C \& H., Gaya \\ ${ }^{2}$ Associate Professor, Deptt. of biochemistry, VIMS, Pawapuri, Nalanda \\ ${ }^{3}$ Assist. Professor, Deptt. of Biochemistry, VIMS, Pawapuri, Nalanda \\ *Corresponding Author \\ Dr Usha Kumari \\ Associate Professor, Deptt. of biochemistry, VIMS, Pawapuri, Nalanda
}

\section{Introduction}

ATHEROSCLEROSIS has become a major health problem in Indian patients now a day. It results in coronary artery disease leading to myocardial infarction (MI) and carotid artery occlusion causing strokes and cerebrovascular accidents .The terms atherosclerosis was coined by JeanFrederick Lobstein (1833). William Potter (1893) provided experimental evidence of occlusion of coronary arteries resulting in death due to myocardial infarction. Initially there was impression that atherosclerosis is an age related degenerative process which affects the person of affluent society mainly obese, sedentary and stressed males. Now a day many study has discovered that smoking is also an important and preventable cause of cardiovascular morbidity and mortality in Indian population. In India, smoking in the form of cigarette in high income group patients and bidi in lower socio-economic group is very popular particularly in stressed person. There are several factors to explain atherosclerosis among Indians population: sedentary life, rapid urbanisation, industrialisation and singular family concept resulting in stress, faulty lifestyle, smoking, also there is inherent genetic predispositions to cardiovascular disease, dyslipidemia and central obesity. Out of these smoking and tobacco consumption-have played the crucial and additive role in stressed personality person. According to the World health organisation South- East Asia Regional office cardiovascular disease caused 3.493 millions death in this region out of which coronary artery disease account for 1.706 millions death. A total of 1.375 millions deaths occurred in India alone because of cardiovascular disease. It was estimated that the incidence of cardiovascular disease would increase from 2.90 crore in 2002 to about 6.40 crore in 2015 . It was observed that by the year 2020, coronary heart disease and stroke would occupy the first and fourth places as the leading causes of disability and mortality in Indian. India is one of the largest producer and exporter of tobacco in the world. Smoking leads to coronary artery occlusion and constriction, tachycardia, platelet adhesions and aggregation, activates caspase-3 which induces apoptosis of 
endothelial cells. Smoking also impairs the activity of endothelial nitric oxide synthase. It promotes the dyslipidemia (i.e. LDL-C). It promotes LDL-C oxidation and decreases HDL. It is responsible for increased plasma fibrinogen and catecholamine which causes systemic vasculitis. It accelerates the aging process, facilitates mutant gens for insulin resistance syndrome (IRS) and hence increases the rate of diabetes among smokers. In this way smoking is largely responsible for the hypertension, premature atherosclerosis and many cardiovascular and cerebrovascular disorders like myocardial infraction and strokes respectively. Tobacco smoke is complexed, dynamic and reaction mixture containing nitrosamines (alkaloid). Many of them can harm our body in various ways. Tobacco smoking is well known modified risk factor for atherosclerosis, coronary heart disease, lung and oral cancers, chronic obstructive pulmonary diseases, etc. Nicotine is one of the toxins present in tobacco smoke. It is found to have effects on catecholamine and cortisol secretion. Elevated catecholamine and cortisol secretion can alter carbohydrate and lipid metabolism in such person. Alteration in lipid metabolism may lead to dyslipidemic changes which may become a predisposing factor for atherosclerosis and ischemic heart disease leading morbidity and mortality in smokers.

\section{Aims and Objectives}

Nicotine of tobacco can be attributed to change in lipid profile and its atherogenic complications. This study was done to compare these changes and to evaluate role of estimation of lipid profile among smokers and non smoker as a predictor of atherosclerosis and related diseases.

\section{Material and Method}

Present study was carried out at Anugrah Narayan Magadh Medical College Gaya in the department of biochemistry of Central Research Laboratory.

A total 120 person were evaluated in which 60 male chronic smokers who were smoke for more than 20years, with an age ranging between 50 to 60years, were included in this study (Group 1). 60 male non-smokers whose age and weight was approximately matched with person in group 1 were recruited as control (Group 2). Controls were clinically healthy and from same socio-economic and age group. The following criteria were used for exclusion

1) Alcoholic

2) Ex-smokers

3) Diabetes mellitus

4) Renal disease

5) Hypertension

6) Family history of cardiovascular disorder

7) Chronic hepatic dysfunction

8) Endocrine disorder and obesity

9) Patient taking Lipid lowering drug

10) Patient already diagnosed for atherosclerotic disorder

\section{Criteria for Inclusion}

1) Male patients

2) Smokers for more than 20years

3) Age group 50- 60years

4) Patient of both higher and lower socioeconomic group.

Venous blood samples were collected after 12 hours of an overnight fasting into plain vial, serum was obtained by centrifugation and sample were immediately separated. Total cholesterol, triglycerides, LDL-C and HDL-C level were analysed on Erba- chem-7 semiautoanalyser, colorimetric method. In case of Total cholesterol, method is based on the determination of 4cholesterone after enzymatic cleavage of cholesterol ester by cholesterol esterase, conversion of cholesterol by cholesterol oxidase and subsequent measurement by the Trinder reaction of hydrogen peroxide formed. The reference range of normal, borderline and high total cholesterol was $<200,200-250,>250 \mathrm{mg} / \mathrm{dl}$ respectively. The method of triglycerides estimation based on the work by Wahlefeld using a lipoprotein lipase from the microorganisms for the rapid and complete hydrolysis of triglycerides 
to glycerol followed by oxidation to dihydroxyacetone phosphate and hydrogen peroxide. This hydrogen peroxide is measured by Tinder end point reaction. The expected value of triglycerides is $<150 \mathrm{mg} / \mathrm{dl}$. The HDL-c is determined enzymatically by cholesterol esterase and cholesterol oxidase compiled with polyethylene glycol to the amino group. Cholesterol esters are broken down quantitavely into free cholesterol and fatty acids by cholesterol esterase. In the presence of oxygen, cholesterol is oxidized by cholesterol oxidase to 4cholesterenone and hydrogen peroxide. Hydrogen peroxide further form due intensity of which determines HDL-C concentration. The expected value of HDL-C in male was $35.55 \mathrm{mg} / \mathrm{dl}$.

\begin{tabular}{|l|c|c|c|}
\hline $\begin{array}{l}\text { Name of } \\
\text { Parameter }\end{array}$ & $\begin{array}{c}\text { Smokers } \\
\text { (Group 1) }\end{array}$ & $\begin{array}{c}\text { Non smokers } \\
\text { (Group2) }\end{array}$ & P-value \\
\hline & $(\mathrm{mg} / \mathrm{dl})$ & Mean \pm SD & Mean \pm SD \\
\hline Total cholesterol & $264.68 \pm 28.9$ & $178.5 \pm 21.2$ & 0.001 \\
\hline Triglyceride & $188.5 \pm 55.42$ & $112.71 \pm 30.1$ & 0.002 \\
\hline LDL- Cholesterol & $190.1 \pm 15.2$ & $105.68 \pm 9.50$ & 0.001 \\
\hline HDL- Cholesterol & $42.2 \pm 3.2$ & $52.72 \pm 5.3$ & 0.001 \\
\hline $\begin{array}{l}\text { VLDL- } \\
\text { Cholesterol }\end{array}$ & $38.2 \pm 10.5$ & $22.14 \pm 6.51$ & 0.001 \\
\hline
\end{tabular}

Serum low density lipoprotein (LDL) and very low density lipoprotein (VLDL) concentration was calculated by Friedwald's formula

LDL $(\mathrm{mg} / \mathrm{dl})=$ total cholesterol $(\mathrm{mg} / \mathrm{dl})-$ HDL $(\mathrm{mg} / \mathrm{dl})-$ Triglycerides $(\mathrm{mg} / \mathrm{dl}) / 5$

$\operatorname{VLDL}(\mathrm{mg} / \mathrm{dl})=$ Triglycerides $(\mathrm{mg} / \mathrm{dl}) / 5$

\section{Results}

Table shows that the mean level of serum total cholesterol, triglycerides, LDL-C and VLDL-C were significantly higher while mean level of serum HDL-C were significantly lower in cases when compared with controls $(\mathrm{p}<0.05)$.

\section{Discussion}

Present study shows comparison of serum lipid profile among smokers and non smokers. Tobacco smoke contains many toxic compounds and free radicals which can alter body metabolic pathways significantly (5). Inhalation of such smoke regularly for long time can aggregate the situation and lead to serious health hazards ${ }^{(6)}$.

In our study, we found significantly elevated levels of serum triglycerides and serum VLDL among smokers than non-smoker. This finding is in accordance with studies done by Sharma $\mathrm{P}$ et al (2016), Mohamed DH et al (2013) and Fariduddin $\mathrm{JM}$ et al (2016).Nicotine is one of the major content of tobacco smoke. Nicotine is found to cause stimulation catecholamine and cortisol secretion. These hormones activate adenyl cyclase in adipose tissue leading to increased lipolysis of stored triglycerides and release of free fatty acid in plasma repeated spikes of their secretion occur in heavy smoker leading to sustain high level of free fatty acid in plasma. These free fatty acids are taken up by hepatocytes and there is increased hepatic triglyceride synthesis. Endogenously synthesized triglycerides are secreted in the form of VLDL particles. Thus, serum level of triglycerides and VLDL are elevated in smokers. Further decrease in HDL-cholesterol in chronic smokers may also be explained by smoking induced increase catecholamine release causing increase in VLDL cholesterol and decrease in HDL-cholesterol of concentration. Thus smoking promotes coronary heart disease and atherosclerosis by lowering the anti atherogenic factor HDL-cholesterol and increasing the potentially atherogenic lipoproteins LDLcholesterol which further may lead to vascular endothelium damage.

\section{Conclusion}

"Smoking is injurious to health" clearly verified by above studies because of a strong relationship between cigarette smoking and increase in serum lipid. In chronic smoker the risk of increase in serum cholesterol with an increase in LDLcholesterol and decrease in HDL-cholesterol reflects a great significance because this is the finding associated with coronary heart disease. Since many other studies also shows that chances of atherosclerosis and its complications are much more in smokers as compared to the non-smokers. 
It is advisable not to smoke if we want to be healthy. Particularly in India were we are living in already polluted environment, smoking should be strictly prohibited.

\section{Bibliography}

1. Murray CJ, Lopez AD, Editors Global Burden of Di; Vol 1: Global burden of disease. A comprehensive of mortality and disability from diereses, injuries and in 1990 and projected to 2020 Geneva; with; 1996.

2. The world health report mental health: New UNO New Hope, 2001; wh, 1211, geneva27, Switzerland 152.

3. Sonaliya K N. The Economics of Tobacco in India. National Journal of Medical Research.2012;2(3):243-244

4. Frienewald WT, Levy RI, Frederickson DS (1972) Estimation of the concentration of low density lipoprotein cholesterol in plasma, without use of preperative ultracentrifuge clinical chem. 18: 489-502.

5. Talhout R, Schulz T, Florek E, Wester P Hazardous compound in tobacco smoke. International Journal of Environmental Research and Public Health 2011;8(2):613-628.

6. Jha P. Ramasundarahettige c, Landsman V, Rostron B, Thun M, Anderson R, et al $21^{\text {st }}$ Century Hazards of smoking and Benefits of cessation in the United States. N England J Med 2013; 368 (4): 341-350.

7. Sharma P, Kuamr P, Sharma R, KK, Gupta G Dyslipidemia among smokers. Asian J Pharm Clin Research2016;9(4):137-138. 